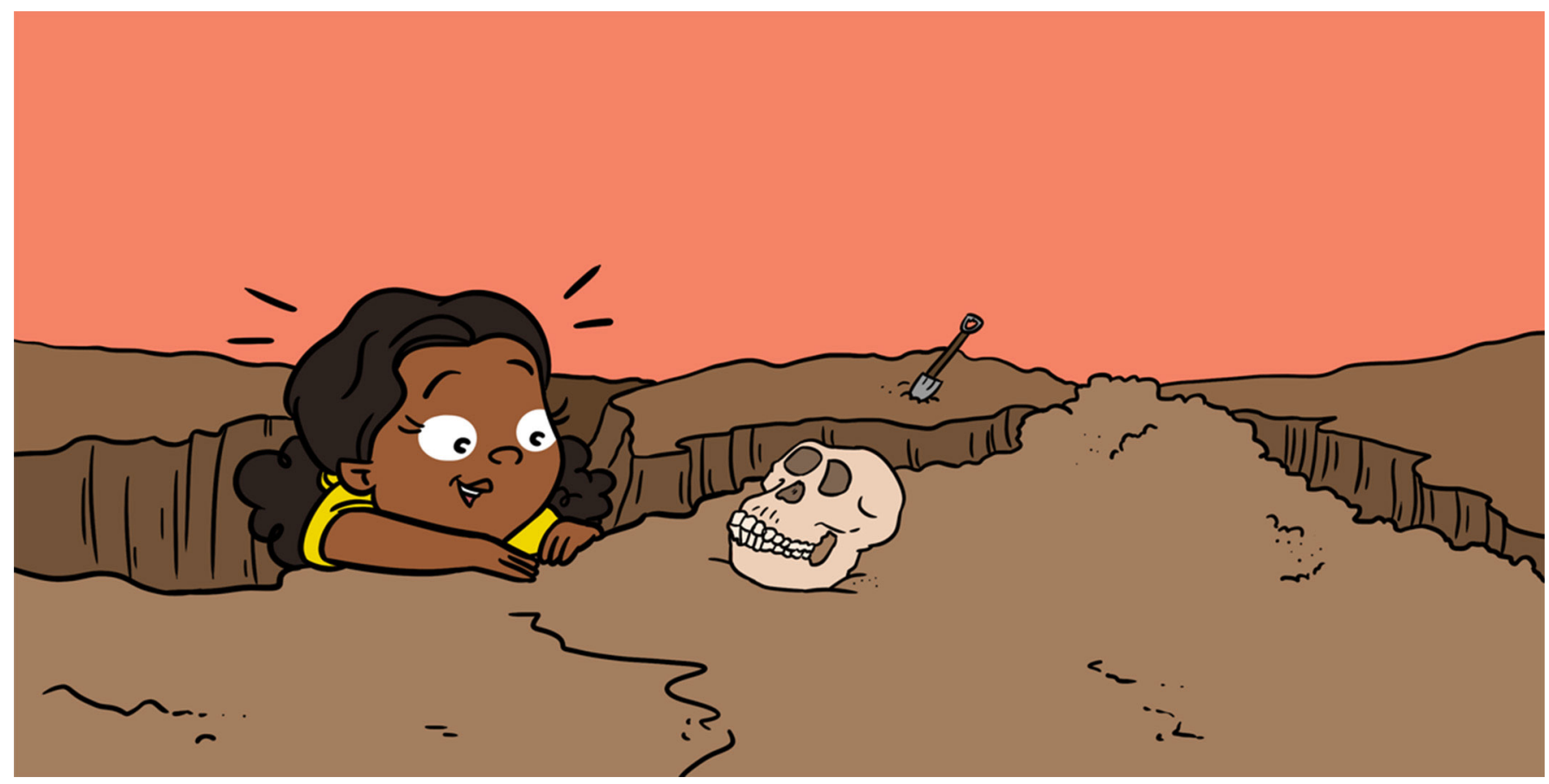

\title{
A BRIEF ACCOUNT OF HUMAN EVOLUTION FOR YOUNG MINDS
}

\section{Theophile Godfraind $^{1 *}$ and Regine Vercauteren Drubbel ${ }^{2}$}

${ }_{1}$ Pole of Pharmacology and Therapeutics (FATH), Institut de Recherche Expérimentale et Clinique, Université Catholique de Louvain, Brussels, Belgium

2 Faculty of Sciences, Anthropology and Human Genetics, Université libre de Bruxelles and Belgian Group for Primatology, Brussels, Belgium

\section{YOUNG REVIEWER:}

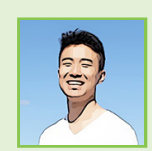

BARTON

AGE: 15
Most of what we know about the origin of humans comes from the research of paleoanthropologists, scientists who study human fossils. Paleoanthropologists identify the sites where fossils can be found. They determine the age of fossils and describe the features of the bones and teeth discovered. Recently, paleoanthropologists have added genetic technology to test their hypotheses. In this article, we will tell you a little about prehistory, a period of time including pre-humans and humans and lasting about 10 million years. During the Prehistoric Period, events were not reported in writing. Most information on prehistory is obtained through studying fossils. Ten to twelve million years ago, primates divided into two branches, one included species leading to modern (current) humans and the other branch to the great apes that include gorillas, chimpanzees, bonobos, and orangutans. The branch leading to modern humans included several different species. When one of these species-known as the 
Neanderthals-inhabited Eurasia, they were not alone; Homo sapiens and other Homo species were also present in this region. All the other species of Homo have gone extinct, with the exception of Homo sapiens, our species, which gradually colonized the entire planet. About 12,000 years ago, during the Neolithic Period, some (but not all) populations of $H$. sapiens passed from a wandering lifestyle of hunting and gathering to one of sedentary farming, building villages and towns. They developed more complex social organizations and invented writing. This was the end of prehistory and the beginning of history.

\section{WHAT IS EVOLUTION?}

Evolution is the process by which living organisms evolve from earlier, more simple organisms. According to the scientist Charles Darwin (1809-1882), evolution depends on a process called natural selection. Natural selection results in the increased reproductive capacities of organisms that are best suited for the conditions in which they are living. Darwin's theory was that organisms evolve as a result of many slight changes over the course of time. In this article, we will discuss evolution during pre-human times and human prehistory. During prehistory, writing was not yet developed. But much important information on prehistory is obtained through studies of the fossil record [1].

SPECIATION

The formation of new and distinct species in the course of evolution.

\section{GENUS}

In the classification of biology, a genus is a subdivision of a family. This subdivision is a grouping of living organisms having one or more related similarities. In the binomial nomenclature, the universally used scientific name of each organism is composed of its genus (capitalized) and a species identifier (lower case), for example Australopithecus afarensis, Homo sapiens.

\section{HOW DID HUMANS EVOLVE?}

Primates, like humans, are mammals. Around ten to twelve million years ago, the ancestral primate lineage split through speciation from one common ancestor into two major groups. These two lineages evolved separately to become the variety of species we see today. Members of one group were the early version of what we know today as the great apes (gorillas, chimpanzees, and bonobos in Africa, orangutans in Asia) (Figures 1, 2); that is, the modern great apes evolved from this ancestral group. They mostly remained in forest with an arboreal lifestyle, meaning they live in trees. Great apes are also quadrupeds which means they move around with four legs on the ground (see Figure 2). The other group evolved in a different way. They became terrestrial, meaning they live on land and not in trees. From being quadrupeds they evolved to bipeds, meaning they move around on their two back legs. In addition the size of their brain increased. This is the group that, through evolution, gave rise to the modern current humans. Many fossils found in Africa are from the genus named Australopithecus (which means southern ape). This genus is extinct, but fossil studies revealed interesting features about their adaptation toward a terrestrial lifestyle. 


\section{Figure 1}

Evolutionary scheme, showing that great apes and humans all evolved from a common ancestor. The Neanderthal picture is a statue designed from a fossil skeleton.

\section{Figure 2}

Great Apes in nature. (above) Arboreal (in trees) locomotion of orangutans and (under) the quadrupedal (four-foot) locomotion of gorillas and chimpanzees.
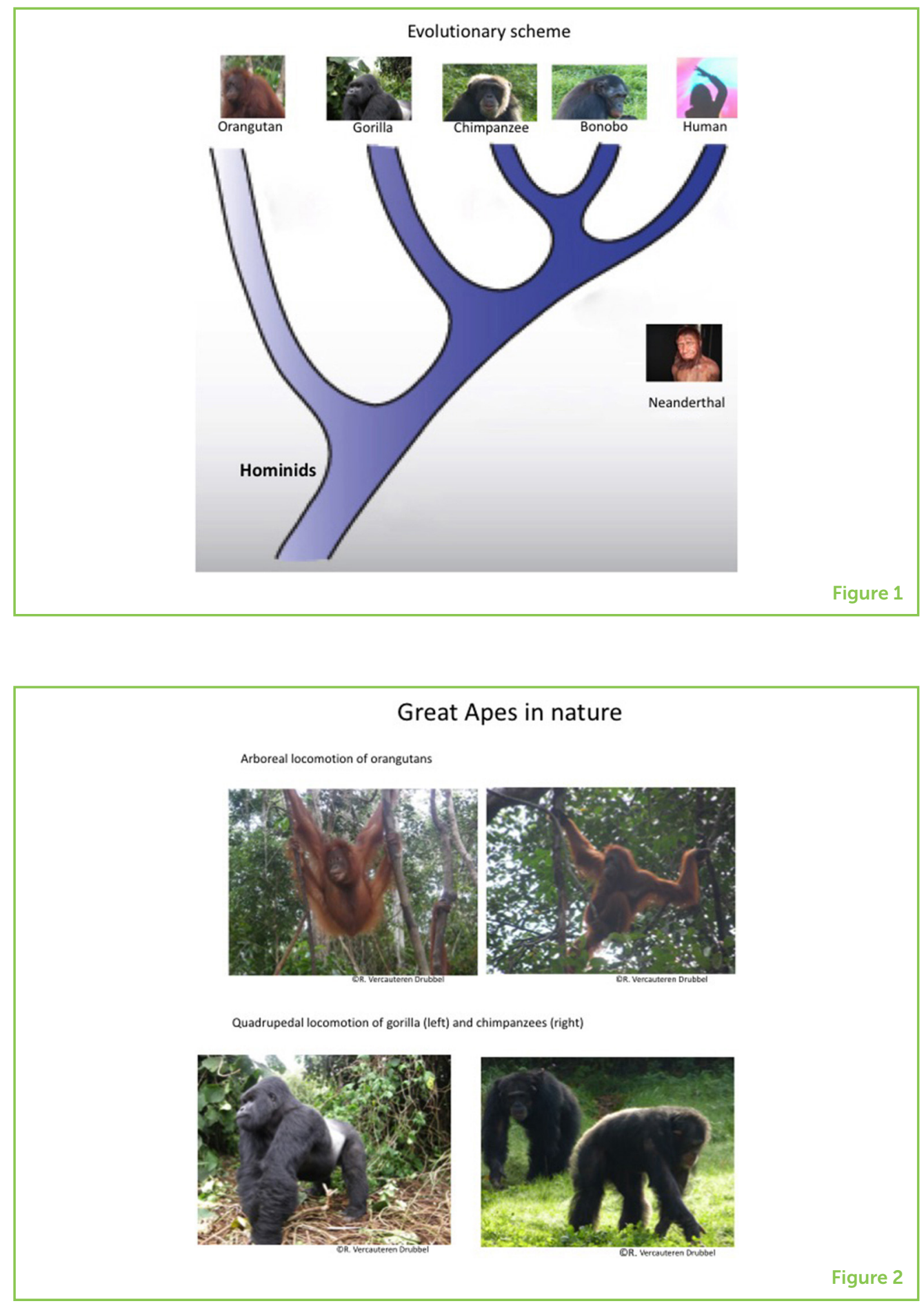

\section{Australopithecus afarensis and Lucy}

In Ethiopia (East Africa) there is a site called Hadar, where several fossils of different animal species were found. Among those fossils was Australopithecus afarensis. In 1974, paleoanthropologists found an almost complete skeleton of one specimen of this species and named it Lucy, from The Beatles song "Lucy in the Sky with Diamonds." The whole world found out about Lucy and she was in every newspaper: she became a global celebrity. This small female-only about $1.1 \mathrm{~m}$ 
tall-lived 3.2 million years ago. Analysis of her femurs (thigh bones) showed that she used terrestrial locomotion. Lucy could have used arboreal and bipedal locomotion as well, as foot bones of another $A$. afarensis individual had a curve similar to that found in the feet of modern humans [2]. Authors of this finding suggested accordingly that $A$. afarensis was exclusively bipedal and could have been a hunter-gatherer.

\section{Homo habilis, Homo erectus, and Homo neanderthalensis}

Homo is the genus (group of species) that includes modern humans, like us, and our most closely related extinct ancestors. Organisms that belong to the same species produce viable offspring. The famous paleoanthropologist named Louis Leakey, along with his team, discovered Homo habilis (meaning handy man) in 1964. Homo habilis was the most ancient species of Homo ever found [2]. Homo habilis appeared in Tanzania (East Africa) over 2.8 million years ago, and 1.5 million years ago became exinct. They were estimated to be about 1.40 meter tall and were terrestrial. They were different from Australopithecus because of the form of the skull. The shape was not piriform (pear-shaped), but spheroid (round), like the head of a modern human. Homo habilis made stone tools, a sign of creativity [3].

In Asia, in 1891, Eugene Dubois (also a paleoanthropologist) discovered the first fossil of Homo erectus (meaning upright man), which appeared 1.8 million years ago. This fossil received several names. The best known are Pithecanthropus (ape-man) and Sinanthropus (Chinese-man). Homo erectus appeared in East Africa and migrated to Asia, where they carved refined tools from stone [4]. Dubois also brought some shells of the time of $H$ erectus from Java to Europe. Contemporary scientists studied these shells and found engravings that dated from 430,000 and 540,000 years ago. They concluded that $H$. erectus individuals were able to express themselves using symbols [5].

Figure 3

A comparison of the skulls of Homo sapiens (Human) (left) vs. Homo neanderthalensis (Neanderthal) (right). You can see a shape difference. From Scientific American Vol. 25, No. 4, Autumn 2016 (modified).

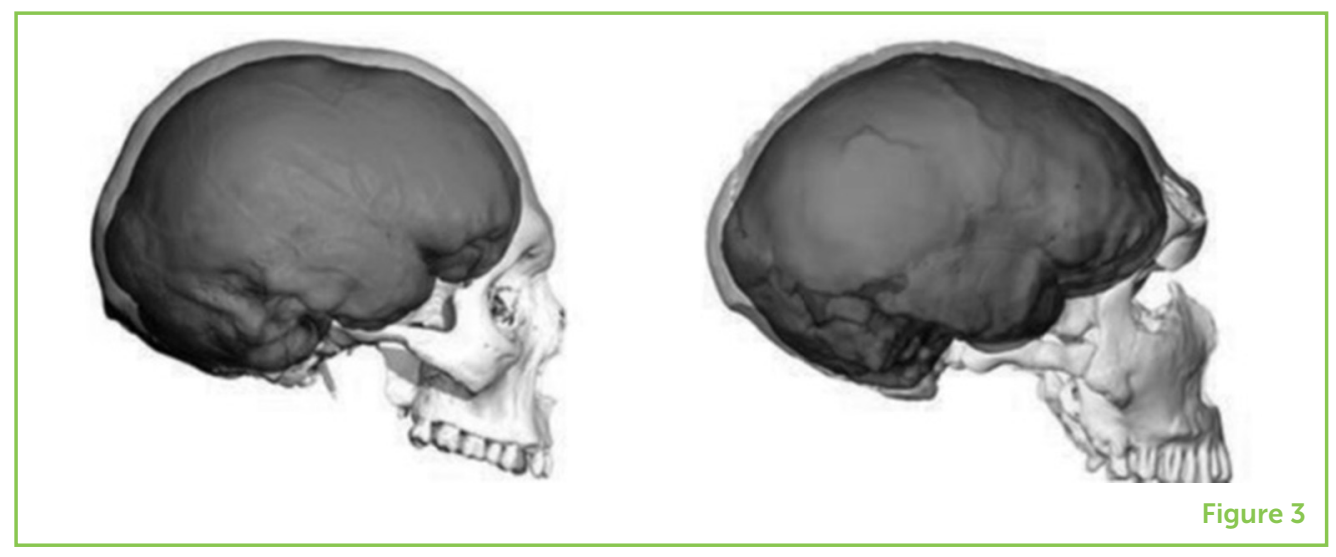


Several Homo species emerged following $H$. erectus and quite a few coexisted for some time. The best known one is Homo neanderthalensis (Figure 3), usually called Neanderthals and they were known as the European branch originating from two lineages that diverged around 400,000 years ago, with the second branch (lineage) Homo sapiens known as the African branch. The first Neanderthal fossil, dated from around 430,000 years ago, was found in La Sima de los Huesos in Spain and is considered to originate from the common ancestor called Homo heidelbergensis [6]. Neanderthals used many of the natural resources in their environment: animals, plants, and minerals. Homo neanderthalensis hunted terrestrial and marine (ocean) animals, requiring a variety of weapons. Tens of thousands of stone tools from Neanderthal sites are exhibited in many museums. Neanderthals created paintings in the La Pasiega cave in the South of Spain and decorated their bodies with jewels and colored paint. Graves were found, which meant they held burial ceremonies.

Denisovans are a recent addition to the human tree. In 2010, the first specimen was discovered in the Denisova cave in south-western Siberia. Very little information is known on their behavior. They deserve further studies due to their interactions with Neandertals and other Homo species (see below) [7].

\section{Homo sapiens}

Fossils recently discovered in Morocco (North Africa) have added to the intense debate on the spread of $H$. sapiens after they originated 315,000 years ago [8]. The location of these fossils could mean that Homo sapiens

\section{Figure 4}

The lions in the Chauvet cave $(-36,000$ years). In this period wild lions were present in Eurasia. Photo: Bradshaw foundation.com. Note the lively character of the picture.

\section{EURASIA}

A term used to describe the combined continental landmass of Europe and Asia.

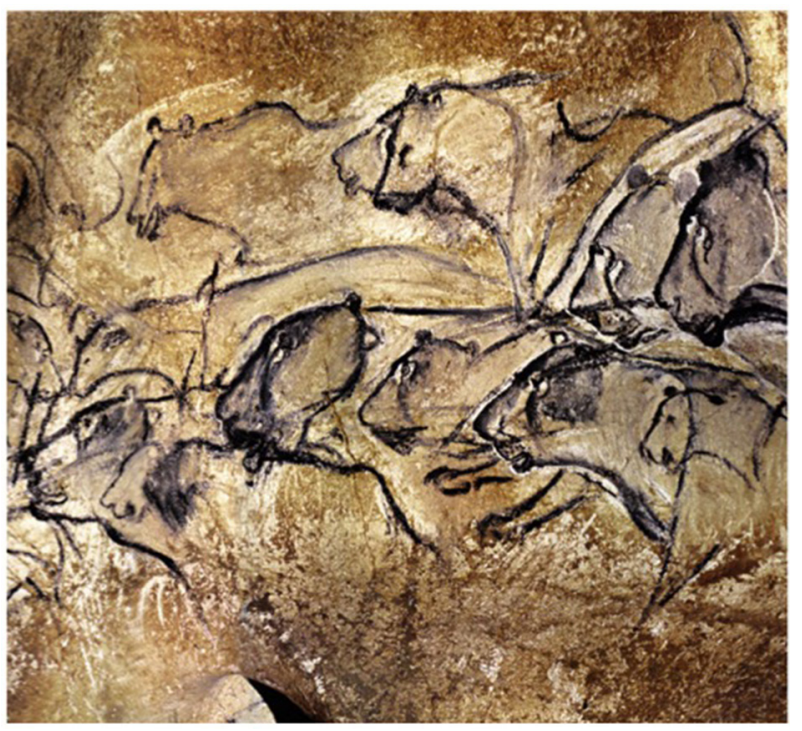

Figure 4 


\section{Figure 5}

Homo sapiens traveled in the world at various periods as shown on the map. They had only their legs to move!

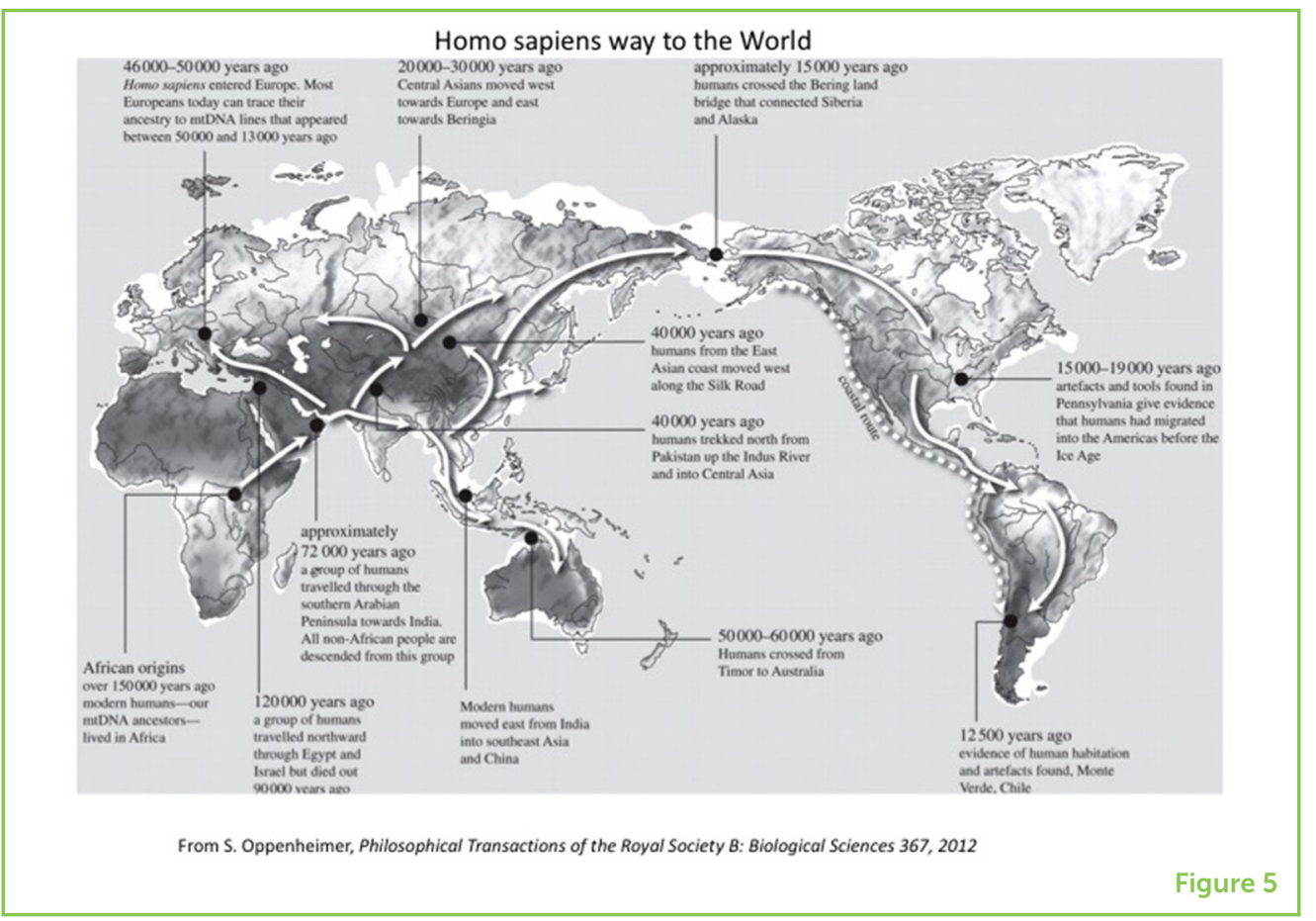

had visited the whole of Africa. In the same way, the scattering of fossils out of Africa indicated their migrations to various continents [9]. While intensely debated, hypotheses focus on either a single dispersal or multiple dispersals out of the African continent $[10,11]$. Nevertheless, even if the origin of the migration to Europe is still a matter of debate [12], it appears that $H$. sapiens was present in Israel [13] 180,000 years ago. Therefore, it could be that migration to Europe was not directly from Africa but indirectly through a stay in Israel-Asia. They arrived about 45,000 years ago into Europe [14] where the Neanderthals were already present (see above). Studies of ancient DNA show that $H$. sapiens had babies with Neanderthals and Denisovans. Nowadays people living in Europe and Asia share between 1 and $4 \%$ of their DNA with either Neanderthals or Denisovans [15].

Several thousand years ago $H$. sapiens already made art, like for example the wall painting in the Chauvet cave $(36,000$ years ago) (Figure 4) and the Lascaux cave (19,000 years ago), both in France. The quality of the paintings shows great artistic ability and intellectual development. Homo sapiens continued to prospect the Earth. They crossed the Bering Land Bridge, connecting Siberia and Alaska and moved south 12,500 years ago, to what is now called Chile. Homo sapiens gradually colonized our entire planet (Figure 5).

\section{THE NEOLITHIC REVOLUTION}

Neolithic Period means New Stone Age, due to the new stone technology that was developed during that time. The Neolithic Period started 
Figure 6

From the beginning to final evolution of cuneiform writing. Writing on argil support showed changes from pictograms to abstract design. Picture modified from British Museum. Dates in year $\mathrm{BC}$.

\section{CLAY}

Fine-grained earth that can be molded when wet and that is dried and baked to make pottery.

\section{REVOLUTION}

Fundamental change occurring relatively quickly in human society.

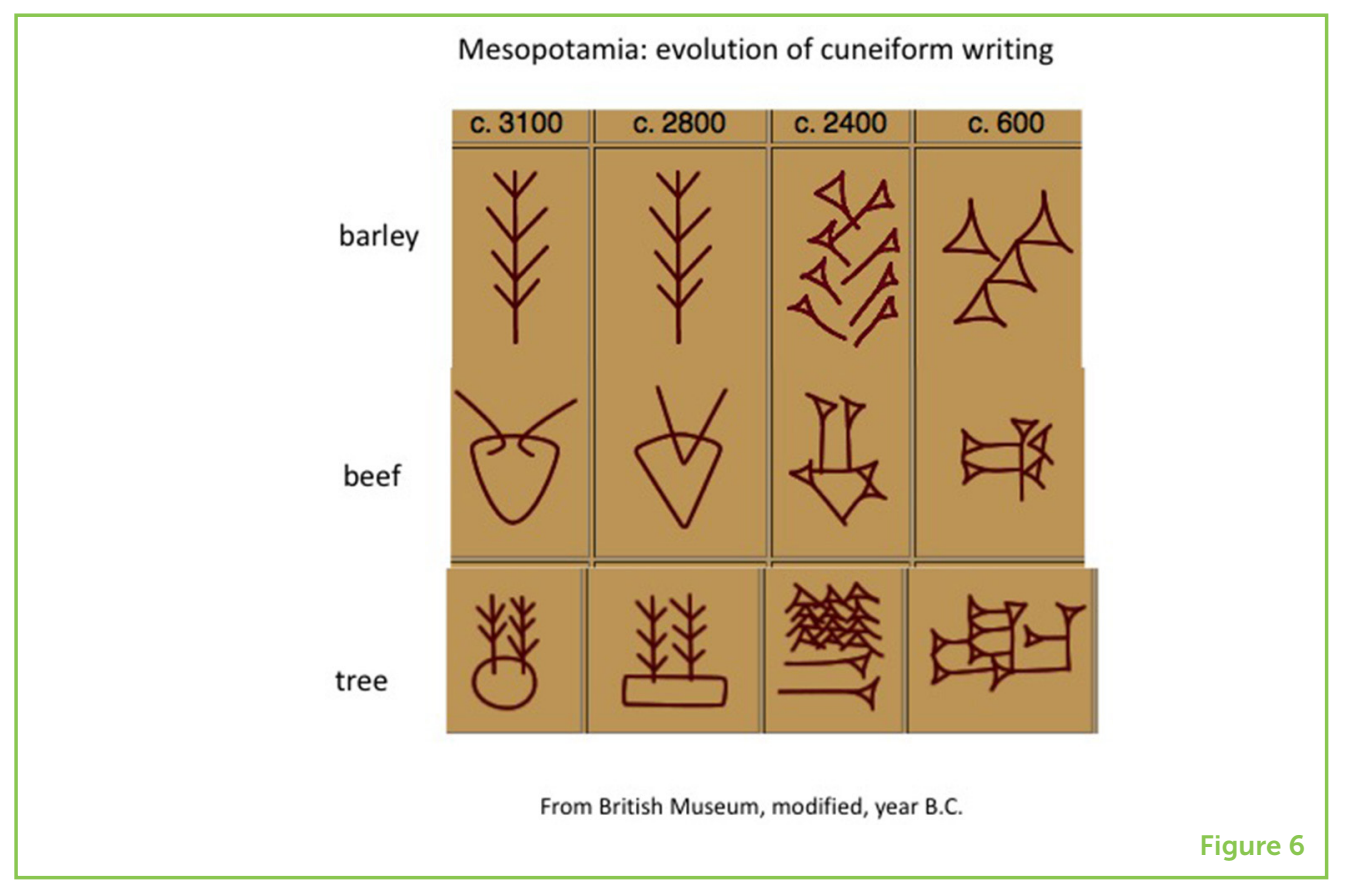

at the end of the glacial period 11,700 years ago. There was a change in the way humans lived during the Neolithic Period. Ruins found in Mesopotamia tell us early humans lived in populated villages. Due to the start of agriculture, most wandering hunter-gatherers became sedentary farmers. Instead of hunting dogs familiar with hunter-gatherers, farmers preferred sheepdogs [16]. In the Neolithic age, humans were farming and herding, keeping goats and sheep. Aurochs (extinct wild cattle), shown in the paintings from the Lascaux cave, are early ancestors of the domesticated cows we have today [17]. The first produce which early humans began to grow in Mesopotamia (a historical region in West Asia, situated between the Tigris and Euphrates rivers) was peas and wheat [18]. Animals and crops were traded and written records were kept of these trades. Clay tokens were the first money for these transactions. The Neolithic Period saw the creation of commerce, money, mathematics, and writing (Figure 6) in Sumer, a region of Mesopotamia. The birth of writing started the period that we call "history," in which events are written down and details of big events as well as daily life can easily be passed on. This tremendous change in human lifestyle can be called the Neolithic Revolution.

\section{CONCLUSION}

From the time of Homo erectus, Homo species migrated out of Africa. Homo sapiens extended this migration over the whole planet. In the fifteenth and sixteenth centuries, Europeans explored the world. On the various continents, explorers met unknown populations. The Europeans were wondering if those beings were humans or not. But actually, 
those populations were also descendants of the men and women who colonized the earth at the dawn of mankind. In much earlier times, there was a theory that there were several races of humans, based mostly on skin color, but this theory was not supported by science. Current studies of DNA show that more than seven billion people who live on earth today are not of different races. There is only one human species on earth today, named Homo sapiens.

\section{SUGGESTED READING}

Species and Speciation. What defines a species? How new species can arise from existing species. https://www.khanacademy.org/science/ biology/her/tree-of-life/a/species-speciation

\section{ACKNOWLEDGMENTS}

The authors thank Emma Clayton (Frontiers) for her advice and careful reading. Photo of Neanderthal statue was from Stephane Louryan, one of the designers of Neanderthal's statue project [Faculty of Medicine, Université libre de Bruxelles (ULB), Brussels, Belgium].

\section{REFERENCES}

1. Godfraind, T. 2016. Hominisation et Transhumanisme. Bruxelles: Académie Royale de Belgique.

2. Ward, C. V., Kimbel, W. H., and Johanson, D. C. 2011. Complete fourth metatarsal and arches in the foot of Australopithecus afarensis. Science 331:750-3. doi: 10.1126/science.1201463

3. Harmand, S., Lewis, J. E., Feibel, C. S., Lepre, C. J., Prat, S., Lenoble, A., et al. 2015. 3.3-million-year-old stone tools from Lomekwi 3, West Turkana, Kenya. Nature 521:310-5. doi: 10.1038/nature14464

4. Carotenuto, F., Tsikaridze, N., Rook, L., Lordkipanidze, D., Longo, L., Condemi, S., et al. 2016. Venturing out safely: the biogeography of Homo erectus dispersal out of Africa. J. Hum. Evol. 95:1-12. doi: 10.1016/j. jhevol.2016.02.005

5. Joordens, J. C., d'Errico, F., Wesselingh, F. P., Munro, S., de Vos, J., Wallinga, J., et al. 2015. Homo erectus at Trinil on Java used shells for tool production and engraving. Nature 518:228-31. doi: 10.1038/nature13962

6. Arsuaga, J. L., Martinez, I., Arnold, L. J., Aranburu, A., Gracia-Tellez, A., Sharp, W. D., et al. 2014. Neandertal roots: cranial and chronological evidence from Sima de los Huesos. Science 344:1358-63. doi: 10.1126/science.1253958 
7. Vernot, B., Tucci, S., Kelso, J., Schraiber, J. G., Wolf, A. B., Gittelman, R. M., et al. 2016. Excavating Neandertal and Denisovan DNA from the genomes of Melanesian individuals. Science 352:235-9. doi: 10.1126/science.aad9416

8. Richter, D., Grun, R., Joannes-Boyau, R., Steele, T. E., Amani, F., Rue, M., et al. 2017. The age of the hominin fossils from Jebel Irhoud, Morocco, and the origins of the Middle Stone Age. Nature 546:293-6. doi: 10.1038/nature22335

9. Vyas, D. N., Al-Meeri, A., and Mulligan, C. J. 2017. Testing support for the northern and southern dispersal routes out of Africa: an analysis of Levantine and southern Arabian populations. Am. J. Phys. Anthropol. 164:736-49. doi: 10.1002/ajpa.23312

10. Reyes-Centeno, H., Hubbe, M., Hanihara, T., Stringer, C., and Harvati, K. 2015. Testing modern human out-of-Africa dispersal models and implications for modern human origins. J. Hum. Evol. 87:95-106. doi: 10.1016/j.jhevol.2015.06.008

11. Templeton, A. 2002. Out of Africa again and again. Nature 416:45-51. doi: $10.1038 / 416045 a$

12. Arnason, U. 2017. A phylogenetic view of the Out of Asia/Eurasia and Out of Africa hypotheses in the light of recent molecular and palaeontological finds. Gene 627:473-6. doi: 10.1016/j.gene.2017.07.006

13. Callaway, E. 2018. Israeli fossils are the oldest modern humans ever found outside of Africa. Nature 554:15-6. doi: 10.1038/d41586-018-01261-5

14. Benazzi, S., Douka, K., Fornai, C., Bauer, C. C., Kullmer, O., Svoboda, J., et al. 2011. Early dispersal of modern humans in Europe and implications for Neanderthal behaviour. Nature 479:525-8. doi: 10.1038/nature10617

15. Vernot, B., and Akey, J. M. 2014. Resurrecting surviving Neandertal lineages from modern human genomes. Science 343:1017-21. doi: $10.1126 /$ science.1245938

16. Ollivier, M., Tresset, A., Frantz, L. A. F., Brehard, S., Balasescu, A., Mashkour, M., et al. 2018. Dogs accompanied humans during the Neolithic expansion into Europe. Biol. Lett. 14:20180286. doi: 10.1098/rsbl.2018.0286

17. Gerling, C., Doppler, T., Heyd, V., Knipper, C., Kuhn, T., Lehmann, M. F., et al. 2017. High-resolution isotopic evidence of specialised cattle herding in the European Neolithic. PLOS ONE 12:e0180164. doi: 10.1371/journal.pone.0180164

18. Revedin, A., Aranguren, B., Becattini, R., Longo, L., Marconi, E., Lippi, M. M., et al. 2010. Thirty thousand-year-old evidence of plant food processing. Proc. Natl. Acad. Sci. U.S.A. 107:18815-9. doi: 10.1073/pnas.1006993107

SUBMITTED: 02 May 2018; ACCEPTED: 01 February 2019;

PUBLISHED ONLINE: 20 March 2019.

EDITED BY: Andrés Juan Rinderknecht, Museo Nacional de Historia Natural, Uruguay

CITATION: Godfraind T and Vercauteren Drubbel R (2019) A Brief Account on Human Evolution for Young Minds. Front. Young Minds 7:22. doi: 10.3389/frym.2019.00022 


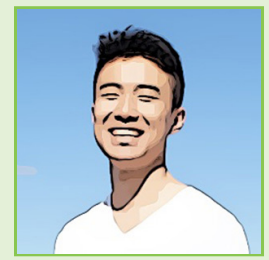

CONFLICT OF INTEREST STATEMENT: The authors declare that the research was conducted in the absence of any commercial or financial relationships that could be construed as a potential conflict of interest.

COPYRIGHT ( 2019 Godfraind and Vercauteren Drubbel. This is an open-access article distributed under the terms of the Creative Commons Attribution License (CC BY). The use, distribution or reproduction in other forums is permitted, provided the original author(s) and the copyright owner(s) are credited and that the original publication in this journal is cited, in accordance with accepted academic practice. No use, distribution or reproduction is permitted which does not comply with these terms.

\section{YOUNG REVIEWER}

\section{BARTON, AGE: 15}

I am a high school student exploring the Sciences. I always felt that scientific articles can be difficult to read and that it would be great to have an organization that simplifies papers for high school students and everyday civilians alike. I pleasantly surprised to find Frontiers for Young Minds! In addition to the Sciences, I also explore Business. In my spare time, I do music and write.

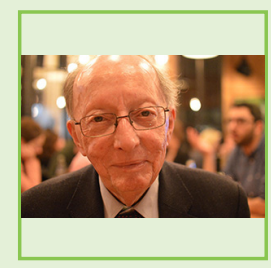

\section{AUTHORS}

\section{THEOPHILE GODFRAIND}

I am an Emeritus Professor of Physiology and Pharmacology at the Université Catholique de Louvain (Louvain-la-Neuve). I am the Founding Field Chief Editor of Frontiers in Pharmacology. I discovered drugs blocking calcium ions entry in cells to produce their activation, for instance initiation of muscle contraction. Those drugs reduce abnormal vascular contraction. They have been successfully used for decades to treat hypertension and other cardiovascular diseases. They are also efficient in excessive neurotransmission leading to cell death. *theophile.godfraindafrontiersin.org

\section{REGINE VERCAUTEREN DRUBBEL}

I am a Belgian Medical Doctor (graduated from the Dutch speaking University of Ghent, UGent) and primatologist (graduated from the French speaking Université Libre de Bruxelles, ULB). For many years I worked as Emergency Doctor. As primatologist I studied mother-infant relation during weaning process in macaques (Cambridge, UK), howler monkeys vocalizations (French Guyana), and phylogeny in Cercopithecus monkeys (Gabon). Passionate by non-human primates, I founded the Belgian Group for Primatology, co-founded the European Federation for Primatology, and supervises ULB students on Chimpanzees (Cameroon), Gorillas (DRCongo), Proboscis monkeys (Borneo Malaysia), Wooly monkeys (Peru), Macaques (Thailand), ... 